\title{
apo B Gene Knockout in Mice Results in Embryonic Lethality in Homozygotes and Neural Tube Defects, Male Infertility, and Reduced HDL Cholesterol Ester and apo A-I Transport Rates in Heterozygotes
}

\author{
Li-Shin Huang, Emanuel Voyiaziakis, Debbie F. Markenson, Karen A. Sokol, ${ }^{*}$ Tony Hayek, and Jan L. Breslow \\ Laboratory of Biochemical Genetics and Metabolism and * Laboratory Animal Research Center, The Rockefeller University, \\ New York 10021
}

\begin{abstract}
apo $B$ is a structural constituent of several classes of lipoprotein particles, including chylomicrons, VLDL, and LDL. To better understand the role of apo $B$ in the body, we have used gene targeting in embryonic stem cells to create a null apo $B$ allele in the mouse. Homozygous apo $B$ deficiency led to embryonic lethality, with resorption of all embryos by gestational day 9. Heterozygotes showed an increased tendency to intrauterine death with some fetuses having incomplete neural tube closure and some live-born heterozygotes developing hydrocephalus. The majority of male heterozygotes were sterile, although the genitourinary system and sperm were grossly normal. Viable heterozygotes had normal triglycerides, but total, LDL, and HDL cholesterol levels were decreased by 37,37 , and $39 \%$, respectively. Hepatic and intestinal apo $B$ mRNA levels were decreased in heterozygotes, presumably contributing to the decreased LDL levels through decreased synthesis of apo B-containing lipoproteins. Kinetic studies indicated that heterozygotes had decreased transport rates of HDL cholesterol ester and apo A-I. As liver and intestinal apo A-I mRNA levels were unchanged, the mechanism for decreased apo A-I transport must be posttranscriptional. Heterozygotes also had normal cholesterol absorption and a normal response of the plasma lipoprotein pattern to chronic consumption of a high fat, high cholesterol, Western-type diet. In summary, we report a mouse model for apo B deficiency with several phenotypic features that were unexpected based on clinical studies of apo B-deficient humans, such as embryonic lethality in homozygotes and neural tube closure defects, male infertility, and a major defect in HDL production in heterozygotes. This model presents an opportunity to study the mechanisms underlying these phenotypic changes. ( J. Clin. Invest. 1995. 96:2152-2161.) Key words: hypobetalipoproteinemia - embryonic stem cells • hydrocephalus • metabolism • development
\end{abstract}

Address correspondence to Li-Shin Huang, Laboratory of Biochemical Genetics and Metabolism, The Rockefeller University, 1230 York Avenue, New York, NY 10021. Phone: 212-327-7700; FAX: 212-327-7165. Tony Hayek's current address is Department of Internal Medicine D, Rambam Medical Center, Haifa 31096, Israel.

Received for publication 24 April 1995 and accepted in revised form 10 July 1995.

J. Clin. Invest.

(c) The American Society for Clinical Investigation, Inc.

$0021-9738 / 95 / 11 / 2152 / 10 \quad \$ 2.00$

Volume 96, November 1995, 2152-2161

\section{Introduction}

apo B is synthesized in both liver and intestine and is an important structural constituent of several classes of lipoproteins, including liver-derived VLDL and its breakdown products IDL and LDL and intestinally derived chylomicrons (1). In humans, mature liver-derived apo B is 4,536 amino acids in length (B100 ), whereas intestinal apo $B$ is roughly half the size and includes only the amino-terminal 2,152 residues $(B-48)(2,3)$. B-100 and B-48 are encoded by a single 43-kb gene containing 29 exons (4). The mechanism for production of two proteins from a single gene involves editing of the primary transcript with the introduction of a stop at codon $2,153(5,6)$. In humans this occurs exclusively in the intestine, whereas in rodents it also occurs in the liver (7).

The importance of apo B in human physiology has been amply documented. Plasma levels of apo B are an important risk factor for coronary heart disease $(8,9)$, and apo $B$ is the ligand for receptor-mediated removal of LDL particles from the circulation (1). Human mutations in the putative LDL receptor binding region of apo $B$ delay LDL clearance and cause increased plasma LDL levels (10). apo $B$ is also required for secretion of lipoprotein particles from the liver and intestine. Humans with abetalipoproteinemia, who degrade apo B intracellularly because they fail to properly lipidate newly synthesized apo B due to homozygosity for genetic defects in the microsomal triglyceride transfer protein $(11-13)$, have little to no circulating VLDL, IDL, LDL, or chylomicrons (1). A similar phenotype is observed in humans with homozygous hypobetalipoproteinemia, due to mutations in the apo B gene that preclude synthesis of the full length protein $(1,14)$. The inability to secrete intestinal apo B in abetalipoproteinemia and homozygous hypobetalipoproteinemia leads to malabsorption of fats causing steattorrhea and failure to thrive and fat-soluble vitamin deficiency causing ataxia, retinitis pigmentosa, and an anemia characterized by acanthocytosis $(1)$. Heterozygotes for hypobetalipoproteinemia are estimated to be $1 / 500-1 / 1,000$ of individuals in the population (14). These individuals are asymptomatic but have $\sim 30-50 \%$ of normal plasma apo B and LDL cholesterol levels (14).

To better understand the role of apo B in the body, we now report the creation by homologous recombination in embryonic stem (ES) ${ }^{1}$ cells of a line of mice containing a germ line mutation in which the first three exons of the apo $B$ gene have been deleted. Based on what has been observed in humans with

1. Abbreviations used in this paper: $\mathrm{C}$, cholesterol; $\mathrm{CE}$, cholesterol ester; ES cells, embryonic stem cells; FCR, fractional catabolic rate; TR, transport rate. 


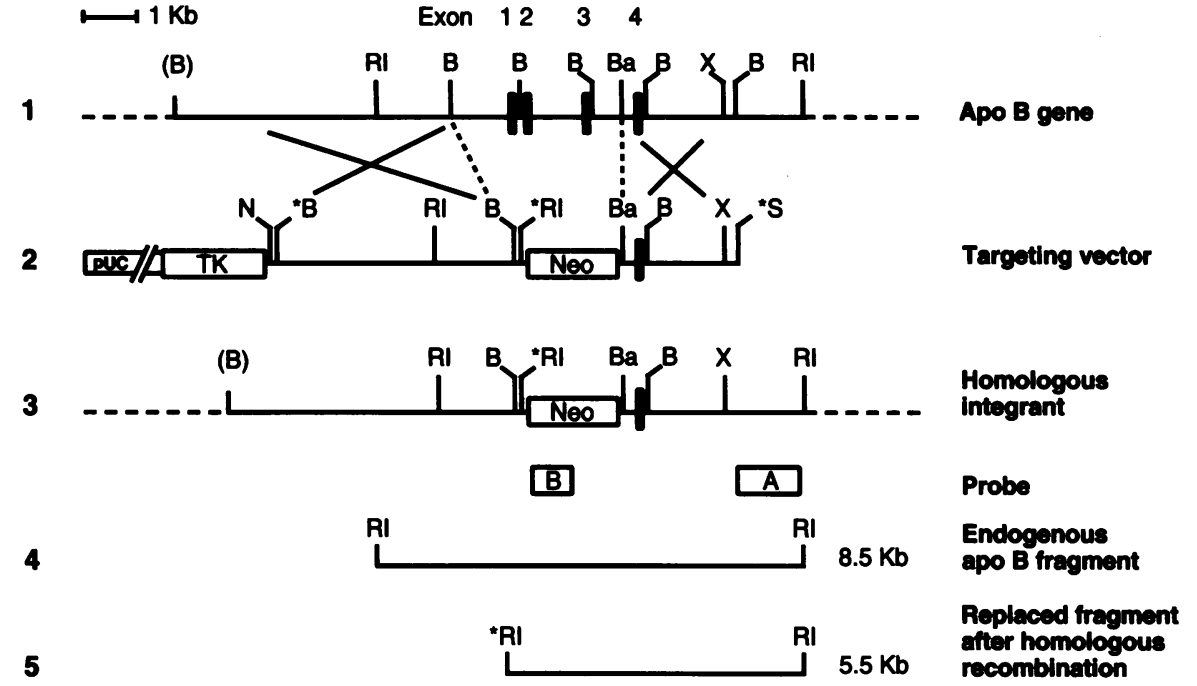

Figure 1. Construction of a mouse apo B gene targeting vector. A partial restriction map of the mouse apo B gene is shown in line 1 . The targeting vector is shown in line 2 . The resulting homologous integrant is shown in line 3. Exons are indicated as solid boxes. Neo and thymidine kinase (TK) genes are shown as open boxes. Restriction enzyme sites are shown in capital letters: $B$, BglII; $B a$, BamHI; $R I$, EcoRI; and $X, \mathrm{XbaI}$. Asterisks indicate sites derived from the vector and parentheses indicate $5^{\prime}$ sites at an undetermined distance. Line 4 shows a predicted 8.5-kb EcoRI fragment from wildtype apo $B$ gene which hybridizes to probe A, a flanking probe 3 ' to the short arm of the targeting vector, or probe $\mathrm{B}$, a fragment containing the Neo gene sequence. Line 5 shows a predicted EcoRI 5.5-kb fragment from a homologous integrant which hybridizes to probe A or B in Southern blot analysis. Result from Southern blot analysis for ES cells is shown in Fig. $2 \mathrm{~A}$. hypobetalipoproteinemia, the apo B knockout mice have an unusual phenotype. Whereas humans with homozygous hypobetalipoproteinemia survive, the homozygous apo B knockout mice are a developmental lethal. Similar observation was also reported recently in mice with the apo B gene disrupted at intron 4 by an insertion vector (15). Moreover, while heterozygous hypobetalipoproteinemic humans are thought to be normal except for reduced LDL, the heterozygous knockout mice have several abnormalities: increased prenatal mortality with a tendency for neural tube defects, decreased fertility in males, and a lipoprotein pattern characterized by strikingly diminished HDL.

\section{Methods}

Construction of apo B gene targeting vector. The mouse apo B gene, isogenic to ES cells, was isolated from an SV129 $\lambda$ genomic library (Stratagene, La Jolla, CA) using a 5' apo B genomic probe. The probe was obtained by PCR amplification of mouse genomic DNA using primers containing sequences from apo $B$ exons 1 and 2 , respectively (16). A partial restriction map of the mouse apo B gene is shown in Fig. 1 (line 1 ). The targeting construction was generated in a pPNT vector containing neomycin resistance $\left(\right.$ neo $\left.^{\mathrm{r}}\right)$ and herpes simplex virus thymidine kinase gene cassettes for positive and negative selection (17). 5.2-kb BglII and 2.5-kb BamHI-XbaI fragments of the mouse apo B gene were inserted at the $5^{\prime}$ and $3^{\prime}$ ends of the neo gene, respectively (Fig. 1, line 2). A unique SfiI site was inserted $3^{\prime}$ to the 2.5-kb BamHI$\mathrm{XbaI}$ fragment for linearization of the vector.

Transfection and culture of ES cells. J1 ES cells (18) were cultured using mouse embryonic fibroblasts as feeder cells (19). The apo B targeting vector $(10 \mu \mathrm{g})$ was linearized with SfiI and electroporated into ES cells $\left(20-25 \times 10^{6}\right)$ in $0.9 \mathrm{ml}$ of ES medium (19) at $200 \mathrm{~V}$ and $800 \mu \mathrm{F}$ (BRL Cell-Porator; Life Technologies, Gaithersburg, MD). Stable integrants were selected using $350 \mu \mathrm{g} / \mathrm{ml}$ of G418 and colonies picked into 96-well plates $10 \mathrm{~d}$ after transfection. After expansion to a 24-well plate, half of each clone was frozen with the remaining cells used for Southern blot analysis.

Southern blot analysis. ES cell DNA was isolated by digesting cells

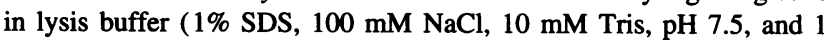
mM EDTA) with $625 \mu \mathrm{g} / \mathrm{ml}$ of proteinase $\mathrm{K}$ at $55^{\circ} \mathrm{C}$ overnight. Genomic DNA was spooled after precipitation in two vol of $100 \%$ ethanol.
For Southern blot analysis, 5-10 $\mu \mathrm{g}$ of genomic DNA was digested with EcoRI and analyzed as described previously (20). An external apo $\mathrm{B}$ probe 3 ' to the $2.5-\mathrm{kb}$ BamHI-Xbal fragment and a probe containing the neo gene (Fig. 1, line 3) were used for screening both DNA samples from ES cells and mouse tail tips.

Generation and genotypic analysis of chimeric and mutant mice. ES cells containing a copy of the null apo B allele were expanded and microinjected into 3.5-d-old host blastocysts derived from C57BL/6J mice. The blastocysts were then surgically implanted into the uterine horn of surrogate mothers as described previously (21). All resulting chimeric mice were crossed to $\mathrm{C} 57 \mathrm{BL} / 6 \mathrm{~J}$ mice and germ line transmission was scored by coat pigment. F1 heterozygotes were identified by Southern blot analysis of tail tip DNA. Tail tip DNA was prepared by rocking tail tips in lysis buffer ( $10 \mathrm{mM}$ EDTA, $0.5 \% n$-lauroylsarcosine, $0.1 \mathrm{M}$ Tris- $\mathrm{HCl}, \mathrm{pH} 8.0,0.2 \mathrm{M} \mathrm{NaCl}, 4 \mathrm{M}$ urea) with $1 \mathrm{mg} / \mathrm{ml}$ of proteinase $\mathrm{K}$ at $55^{\circ} \mathrm{C}$ overnight. Tail tip DNA was spooled and subjected to Southern blot analysis as described for ES cell DNA. Positive F1 heterozygotes were backcrossed to $\mathrm{C} 57 \mathrm{BL} / 6 \mathrm{~J}$ to expand the colony and resulting N2 progeny were intercrossed to generate homozygotes.

Genotypic and phenotypic analysis of mutant embryos. Timed pregnancies were set up for both heterozygous intercrosses and backcrosses. The day of the vaginal plug was defined as day 0 of gestation. Embryos were dissected at various stages of development and examined for gross morphology. Embryos were fixed in $10 \%$ formaldehyde in phosphate buffer and photographed under a Nikon SMZ-10 stereomicroscope. Visceral yolk sacs were removed for DNA isolation as described for tail tips. DNA samples were then subjected to Southern blot analysis or PCR analysis if DNA yield was low. For PCR analysis, two sets of reactions were carried out. The first set was to detect a 390-bp fragment present in the wild-type allele but deleted in the null allele. The following primers were used: sense, 5'-TACTAAGCTTGGACACCAGCGTCTGGG-3'; antisense, 5'-TGGACAGCTGAAGCTTAAGTTTTCCAGGAC-3'. To detect the null apo B allele, a second set of primers corresponding to sequences in the neo gene was used to detect an 800bp neo fragment. The primers used were: sense, $5^{\prime}$-ATGGGATCGGCCATTGAACAAG- $3^{\prime}$; antisense, 5'-ACTCGTCAAGAAGGCGATAGAAGG-3'. Samples were amplified for 35 cycles $\left(92^{\circ} \mathrm{C}\right.$ for $1 \mathrm{~min}$; $65^{\circ} \mathrm{C}$ for $1 \mathrm{~min} ; 72^{\circ} \mathrm{C}$ for $2 \mathrm{~min}$ ). Amplified bands were visualized on $1.2 \%$ agarose gels by ethidium bromide staining.

Pathologic evaluation of apo B heterozygotes. Live heterozygotes and wild-type control, age-, and gender-matched littermates were exam- 
ined for gross and microscopic pathology. Heads with skin excised were removed, fixed in $10 \%$ buffered formalin, and then decalcified ( $\mathrm{S} / \mathrm{P}$ decalcifying solution; Baxter Scientific, Deerfield, IL). Sequential cross sections $(2 \mathrm{~mm})$ of the head were performed for histopathologic evaluation (22). The tissues were processed routinely, embedded in paraffin, cut at 5-6 $\mu \mathrm{m}$, and stained with hematoxylin and eosin (22).

Lipid and lipoprotein analyses. Mice used for all experiments in the compositional and metabolic studies described throughout the text were age- (10-12 wk) and gender-matched. For diet studies, mice were fed with either regular rodent chow (PicoLab rodent chow 20, No. 5053; Purina Lab Chows, St. Louis, MO) or Western-type diet (No. 88137; Teklad Premier Laboratory Diets, Madison, WI). Rodent chow consisted of $4.5 \%$ (wt/wt) fat, $0.02 \%$ (wt/wt) cholesterol and was free of casein and sodium cholate and the Western-type diet consisted of $21 \%$ (wt/wt) fat (polyunsaturated/saturated $=0.07), 0.15 \%(w t / w t)$ cholesterol, $19.5 \%$ casein and was free of sodium cholate (23). All lipid and lipoprotein analyses were performed on individual mice after an 8-h fast. Food was removed at 8:00 a.m. and blood was drawn from the retroorbital venous plexus into EDTA tubes at 4:00 p.m. the same day. Blood samples for apo B detection were collected in tubes containing EDTA and a protease inhibitor mix (24). Cholesterol and triglyceride analysis was performed using enzymatic assay kits (No. 81602; Boehringer Mannheim Corp., Indianapolis, IN and No. 334-A; Sigma Immunochemicals, St. Louis, MO, respectively). For quantification, lipoproteins were separated at buoyant densities $d>1.006$ grams $/ \mathrm{ml}$ by airfuge ultracentrifugation (Beckman Instruments, Inc., Fullerton, CA). apo Bcontaining lipoproteins were precipitated by addition of dextran sulfate $\mathrm{Mg}^{+2}$ solution (HDL cholesterol reagent, No. 352-3; Sigma Immunochemicals) to obtain HDL fractions as described previously (25). Both fractions of lipoproteins ( $d>1.006 \mathrm{grams} / \mathrm{ml}$ and HDL) were subjected to cholesterol analysis. LDL cholesterol (LDL-C) is the difference between $d>1.006$ grams/ml and HDL, and VLDL cholesterol (VLDLC) is the difference between total cholesterol and $d>1.006$ grams $/ \mathrm{ml}$. In the HDL fraction, free cholesterol and total cholesterol were measured by gas chromatography with coprostanol as an internal standard (25). HDL cholesterol ester (CE) was the difference between free cholesterol and total cholesterol.

For FPLC size fractionation, $200 \mu \mathrm{l}$ of pooled and filtered mouse plasma was injected onto two Superose-6 columns in tandem (Pharmacia LKB Biotechnology, Piscataway, NJ) and eluted at a constant flow rate of $0.3 \mathrm{ml} / \mathrm{min}$ with $1 \mathrm{mM}$ EDTA and $0.15 \mathrm{M} \mathrm{NaCl}$ (26) Fractions of $0.5 \mathrm{ml}$ were collected and cholesterol concentrations were measured enzymatically.

In vivo HDL turnover studies. HDL turnover studies were carried out using doubly labeled HDL as described previously (25), except mouse A-I was purified from pooled plasma samples of control mice and then subjected to iodination. HDL-CE was labeled with ${ }^{3} \mathrm{H}$-cholesteryl oleoyl ether previously dissolved in intralipid and transferred into HDL by cholesteryl ester transfer protein from $d>1.25$ grams $/ \mathrm{ml}$ rabbit plasma. Before injection, 2-4 $\mu \mathrm{g}$ of ${ }^{125} \mathrm{I}$-mouse A-I ( sp act $=200$ $\mathrm{cpm} / \mathrm{ng}$ ) was mixed with mouse HDL labeled with ${ }^{3} \mathrm{H}$-cholesteryl oleoyl ether (100,000-200,000 dpm). Before experiments, blood was drawn from fasted mice for measurements of HDL cholesterol and apo A-I levels. Mice were injected in the femoral vein with doubly labeled HDL. Blood $(100 \mu \mathrm{l})$ was taken at $10 \mathrm{~min}, 90 \mathrm{~min}, 3 \mathrm{~h}, 8 \mathrm{~h}$, and $24 \mathrm{~h}$. Plasma $(20 \mu \mathrm{l})$ from each time point was counted in a gamma counter for the radioactivity of ${ }^{125} \mathrm{I}$-apo A-I. Another aliquot of plasma sample $(40 \mu \mathrm{l})$ was extracted with hexane and the radioactivity of ${ }^{3} \mathrm{H}$-cholesteryl oleoly ether was measured in a liquid scintillation counter. Fractional catabolic rates (FCRs) for apo A-I and HDL-CE were calculated from the plasma decay curves of ${ }^{125} \mathrm{I}$-apo A-I and ${ }^{3} \mathrm{H}$-cholesteryl oleoyl ether assuming a two-pool model as in the Matthews method (27).

Western blot analysis. Mouse plasma samples were diluted with $0.9 \% \mathrm{NaCl}$, added to equal volume of $2 \times$ Laemmli buffer, and boiled for $5 \mathrm{~min}$ before SDS-PAGE (28). For apo B detection, $10 \mu \mathrm{l}$ of plasma was separated in $5 \%$ separating/4\% stacking gels. For apo A-I detection, $1 \mu \mathrm{l}$ of plasma was separated in $10 \%$ separating/5\% stacking gels. For apo A-I quantification, serial dilutions of mouse plasma with known apo A-I concentration were used as standards. Proteins were transferred from SDS-PAGE to nitrocellulose membrane as described (29). Rabbit anti-rat apo B antibody crossreacting with mouse apo B (gift of Dr. David Usher, University of Delware, Newark, DE) and rabbit antimouse apo A-I antibody were used. Reactions between apolipoproteins and antibodies were detected by ECL reagent (Amersham Corp., Arlington Heights, $\mathrm{IL}$ ) and exposed to $\mathrm{x}$-ray films. For quantification, autoradiograms were scanned with a densitometer.

Northern blot analysis. Both liver and intestinal tissues were removed from heterozygotes and wild-type littermates and RNA was isolated using the guanidinium thiocyanate method (30). Total cellular RNA of $10 \mu \mathrm{g}$ from each tissue was separated on $6 \%$ formaldehyde/ agarose gels and then transferred to a nylon membrane. Hybridizations were carried out as described previously (24). For apo B or apo A-I mRNA detection, 0.8 and $1.5 \%$ agarose gels were used, respectively. A human cDNA probe containing $6 \mathrm{~kb}$ of human apo $\mathrm{B}$ sequences in exon 26 (24) and a mouse apo A-I cDNA riboprobe (25) were used to detect apo B and apo A-I mRNA, respectively. A mouse $\beta$-actin riboprobe (Ambion Inc., Austin, TX) was used in each experiment to normalize the loading of RNA samples. For quantification, autoradiograms were scanned with a densitometer.

Intestinal cholesterol absorption. Intestinal cholesterol absorption was determined in six heterozygotes and eight wild-type littermates maintained on a chow diet by the dual-label technique described (31, 32). ${ }^{3} \mathrm{H}$-cholesterol and ${ }^{14} \mathrm{C}$-cholesterol in toluene solvent (Amersham Corp.) were dried under nitrogen gas and then resuspended in ethanol and followed by dilution to a final concentration of $2.5 \%$ with $0.9 \% \mathrm{NaCl}$ and skim milk, respectively. After an 8-h fast, mice were intravenously injected with $10 \mu \mathrm{Ci}$ of ${ }^{3} \mathrm{H}$-cholesterol (in $0.9 \% \mathrm{NaCl}$ ) and fed with 10 $\mu \mathrm{Ci}$ of ${ }^{14} \mathrm{C}$-cholesterol (in skim milk) as an intragastric bolus. Mice were bled at $21,39,45,62$, and $69 \mathrm{~h}$ after administration of radiolabeled cholesterol and $60 \mu \mathrm{l}$ of plasma was counted in a liquid scintillation counter. The ratio of ${ }^{14} \mathrm{C}$-cholesterol to that of ${ }^{3} \mathrm{H}$-cholesterol was measured at each time point to determine the percentage of cholesterol absorbed.

\section{Results}

Creation of a mouse with a null apo $B$ allele. We have targeted the apo B gene at the $5^{\prime}$ end to create ES cells with a null mutation as shown in Fig. 1.500 neo resistant ES clones were screened and only one was a homologous integrant as shown in Fig. $2 A$, lane 2 . The mutant 5.5 -kb fragment also hybridized to a probe containing the neo gene sequence (probe B, Fig. 1, line 3 ) which confirmed the homologous recombination event (data not shown). 27 male chimeras were generated from microinjection of the positive ES clone. Seven of these chimeras gave agouti pups, but only one transmitted the null apo $B$ allele through the germ line as shown in lane 2 of Fig. $2 B$. This chimera bred infrequently and yielded small litter sizes when crossed with female C57BL/6J mice. To obtain sufficient numbers of heterozygotes for analysis, heterozygous mice (F1) derived from chimera/C57BL/6J crosses were backcrossed to $\mathrm{C} 57 \mathrm{BL} / 6 \mathrm{~J}$ mice and the resulting heterozygotes (N2) were used for analysis. In the course of breeding, it was noted that twothirds of the heterozygous apo B knockout male studs, derived from either F1 or N2 backcrosses, were sterile. Male studs were routinely tested for fertility at the age of $2 \mathrm{mo}$. Sterility was defined as failure to impregnate female $\mathrm{C} 57 \mathrm{BL} / 6 \mathrm{~J}$ mice over a duration of 4 mo.

Transmission of the null apo B allele in heterozygous intercrosses and backcrosses. Fertile N2 heterozygotes were intercrossed and no live homozygotes were born, as shown in Table 


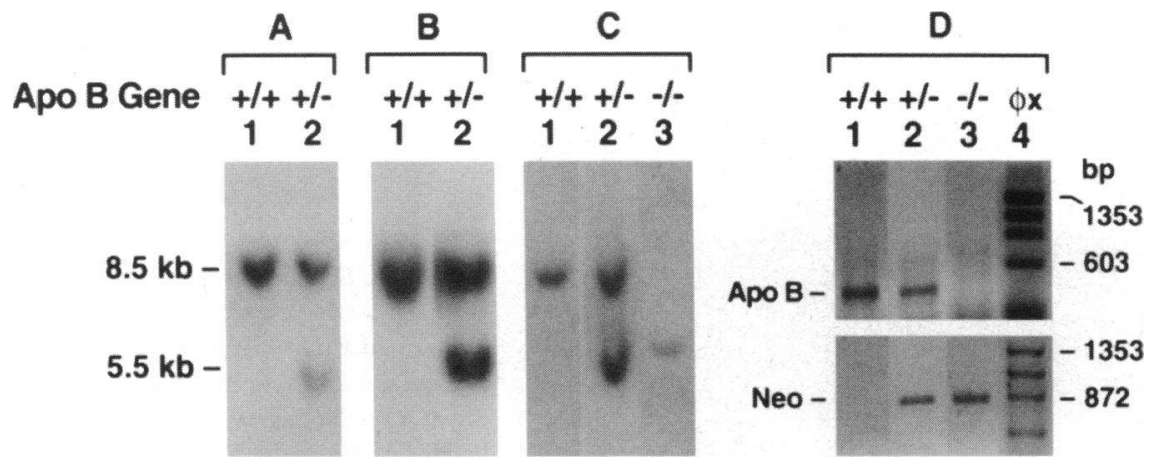

Figure 2. Genotype analyses of ES clones, mouse tail tips, and embryos. Southern blot analysis was used to genotype apo B genes in $\mathrm{Neo}^{\mathrm{r}}$ ES clones $(A)$, offspring from chimera and $\mathrm{C} 57 \mathrm{BL} / 6 \mathrm{~J}$ crosses $(B)$, and embryos from heterozygote intercrosses and backcrosses $(C)$. PCR analysis was also used to genotype some of the embryos reported $(D)$. apo B genotype is indicated above each lane: $+/+$ for wildtype ES cells, mice, or embryos; $+/-$ for heterozygotes, and $-1-$ for homozygotes of apo B deficiency. $\phi 174$ HaeIII-digested DNA fragments were used as size markers in lane 4 of $D$. In Southern blot analysis, wild-type

apo B gene is identified by an 8.5-kb EcoRI fragment and targeted apo B gene from homologous integrant is identified by a 5.5-kb EcoRI fragment In PCR analysis, wild-type allele was detected by a 390-bp apo B fragment absent in the targeted apo B allele (top panel of D); targeted apo B allele was detected by an 800 -bp neo fragment (bottom panel of $D$ ).

I. In the same cross, the ratio of heterozygotes to wild-type animals was 1.4 , which is less than the expected ratio of 2 . In backcrosses between $\mathrm{F} 1$ and $\mathrm{N} 2$ heterozygotes and C57BL/ $6 \mathrm{~J}$ mice, there were also less than the expected numbers of heterozygous offspring (Table I). The percentage of live heterozygous offspring from $\mathrm{F} 1$ backcrosses was $41 \%$ and from N2 backcrosses $33 \%$, which both were significantly lower than the expected $50 \%$ (Table I). These data indicate that homozygosity for an apo B null allele is an embryonic lethal in the mouse and suggest that there are also significant numbers of heterozygous apo B knockout animals dying in utero.

Gross morphological examination indicated abnormalities in live-born heterozygous mice. In the F1, C57BL/ $6 \mathrm{~J}$ backcross 1 of 130 heterozygotes was abnormal showing asymmetrical plagiocephaly characterized by a craniofacial osseous deformity with stenosis of the right orbit. In the N2, C57BL/6J backcross 1 heterozygote was stillborn and had neural dysraphism characterized by defective closure of the overlying cranium, and 9 of 53 live-born heterozygotes $(17 \%)$ were noted to be hydrocephalic at weaning (3-4 wk old). These mice displayed varying degrees of hypoactivity, lethargy, and stupor. They all had enlargement and doming of the calvarium with variable separation of the cranial sutures. Sequential cross sections of the decalcified head demonstrated prominent dilatation of the lateral and third ventricles of the brain with associated marked, cerebral, cortical atrophy (Fig. 3). In two animals, there was also a moderate amount of intraventricular hemorrhage.

Embryos from heterozygous intercrosses and backcrosses.
To determine the gestational age for embryonic lethality in homozygotes, we analyzed the genotypes of embryos from intercrosses by Southern blot (Fig. $2 \mathrm{C}$ ) or PCR analysis (Fig. 2 $D$ ). Of 32 day 9 embryos $25 \%$ were wild-type, $50 \%$ heterozygous, $19 \%$ homozygous knockout, and $6 \%$ untypeable (Table II). All of the homozygous embryos were resorbed with the DNA diagnosis from the remaining visceral yolk sac. Of 25 embryos harvested between days 10 and $15,32 \%$ were wildtype, $52 \%$ heterozygous knockout, and $16 \%$ untypeable (Table II). No homozygous apo B knockout were detected after day 10.

To investigate whether heterozygous apo B knockout mice were dying in utero, embryos from heterozygous intercrosses and backcrosses were analyzed. As shown in Table II, in the intercrosses 10 of 29 heterozygous embryos had abnormalities which were of three general types: complete resorption with residual visceral yolk sac $(3 / 10)$; partial resorption $(2 / 10)$; and gross malformations $(5 / 10)$. The malformations generally consisted of incomplete neural tube closure (Fig. 4), except one embryo with three sets of limbs. The neural tube abnormalities included incomplete closure of the hind portion, mid portion, or entire head region, as well as partial or complete opening of the spinal canal.

Resorption and malformation were also observed in heterozygous embryos from backcrosses. At gestational days 9-11, $54 \%(15 / 28)$ of heterozygous embryos and $25 \%(8 / 32)$ of wild-type embryos were either resorbed or malformed (Table II). At gestational days $12-15$, the $31 \%$ of heterozygous em-

Table I. Live Offspring from Heterozygous Intercrosses and Backcrosses

\begin{tabular}{|c|c|c|c|c|c|c|c|}
\hline \multirow[b]{2}{*}{ Cross* } & \multirow{2}{*}{$\begin{array}{l}\text { Percent C57BL/6J } \\
\text { genetic background }\end{array}$} & \multirow{2}{*}{$\begin{array}{c}\text { No. of total } \\
\text { offspring }\end{array}$} & \multicolumn{3}{|c|}{ apo B genotype ${ }^{\ddagger}$} & \multicolumn{2}{|c|}{$\chi^{2}$ analysis $^{8}$} \\
\hline & & & $+1+$ & $+1-$ & $-1-$ & $\chi^{2}$ & $P$ value \\
\hline Intercross $(\mathrm{N} 2 \times \mathrm{N} 2)$ & $75 \%$ & 53 & $22(42 \%)$ & $31(58 \%)$ & $0(0 \%)$ & 15.6 & $<0.0005$ \\
\hline Backcross $1(\mathrm{~F} 1 \times \mathrm{C} 57 \mathrm{BL} / 6 \mathrm{~J})$ & $75 \%$ & 320 & $190(59 \%)$ & $130(41 \%)$ & & 5.3 & $<0.05$ \\
\hline Backcross $2(\mathrm{~N} 2 \times \mathrm{C} 57 \mathrm{BL} / 6 \mathrm{~J})$ & $87.5 \%$ & 163 & $110(67 \%)$ & $53^{\| \prime}(33 \%)$ & & 9.9 & $<0.005$ \\
\hline
\end{tabular}

* F1 are heterozygous offspring from chimera and C57BL/6J crosses. N2 are heterozygous offspring from F1 backcrosses. ${ }^{\ddagger}$ Expected Mendelian ratios of apo $B$ genotypes for intercrosses $(+/+:+/-:-/-)$ are 1:2:1 (25:50:25\%) and for backcrosses $(+/+:+/-)$ are $1: 1(50: 50 \%)$. ${ }^{8}$ Observed numbers for each genotype were compared with the expected numbers. "Nine of these mice (17\%) were hydrocephalic. 


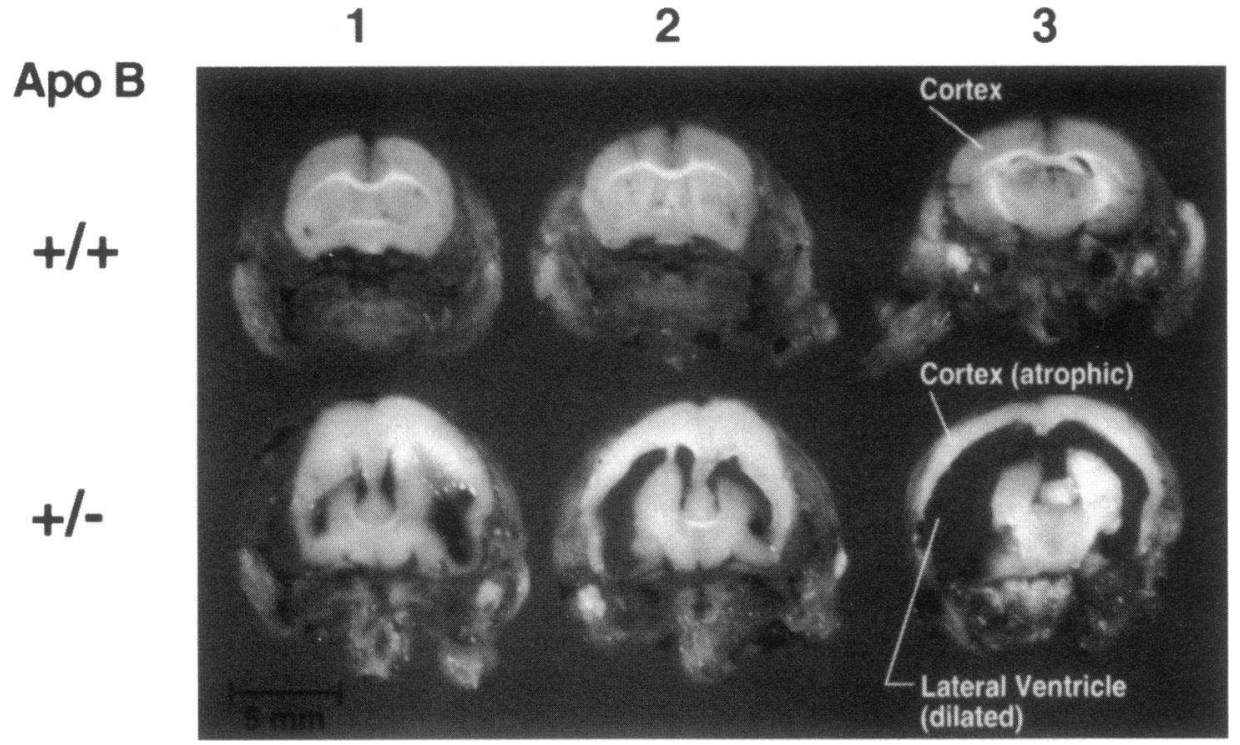

Figure 3. Sequential cross sections of the heads of hydrocephalic heterozygotes and wild-type littermates. Sequential cross sections from heads of a hydrocephalic heterozygote (bottom) and a wild-type littermate (top) were photographed. This figure shows that heterozygous hydrocephalic mouse demonstrated marked dilatation of the lateral and third ventricles with marked cerebral cortical atrophy compared with wild-type littermates. The magnification is indicated by the horizontal bar $(5 \mathrm{~mm})$.

bryos observed was less than the expected $50 \%$. Presuming perinatal death of all abnormal embryos observed in these backcrosses, we project that $35 \%$ of the live-born mice would be heterozygotes (Table II). This projection agrees with the 33$41 \%$ of live heterozygotes observed from backcrosses shown in Table I. These data confirm that death of heterozygous embryos in utero accounted for the reduced numbers of live heterozygous offspring from both intercrosses and backcrosses.

Lipoprotein metabolism in heterozygotes. The fasting plasma lipoprotein profile of the surviving, apparently normal heterozygous apo B knockout mice was compared with wildtype littermates. As shown in Table III, on both chow and Western-type diets triglyceride levels were normal, whereas total cholesterol decreased 37 and 34\%, respectively. The lipoprotein profile by FPLC analysis shown in Fig. 5 revealed de- creased amount and size of HDL and decreased LDL. This was confirmed by direct quantitative lipoprotein analysis which showed 39 and $38 \%$ decreases in HDL-C and 37 and 33\% decreases in LDL-C on the two diets, respectively (Table III).

$H D L-C E$ and apo A-I turnover studies. Quantitatively the major contributor to reduced cholesterol levels in heterozygous apo B knockout mice was the HDL fraction. To evaluate the underlying metabolic mechanism, in vivo turnover studies with HDL doubly labeled with ${ }^{125} \mathrm{I}$-apo A-I and ${ }^{3} \mathrm{H}$-cholesteryl oleoyl ether were performed. After intravenous injection of labeled HDL, the disappearance of plasma radioactivity was measured and the FCRs of HDL-CE and apo A-I were calculated by the Matthews method (27). Transport rates (TRs) for HDL-CE and apo A-I were calculated as the product of FCR and pool size reflected by the plasma concentration of HDL-CE and total

Table II. Embryos from Heterozygous Intercrosses and Backcrosses

\begin{tabular}{|c|c|c|c|c|c|c|c|c|c|}
\hline \multirow[b]{3}{*}{ Cross } & \multirow[b]{3}{*}{ Gestation day } & \multirow[b]{3}{*}{ Total No. } & \multicolumn{7}{|c|}{ apo B genotype } \\
\hline & & & \multirow{2}{*}{$\frac{\text { Unknown* }}{\text { Total }}$} & \multicolumn{2}{|c|}{$+1+$} & \multicolumn{2}{|c|}{$+1-$} & \multicolumn{2}{|c|}{$-1-$} \\
\hline & & & & Total & Abnormal $^{\ddagger}$ & Total & Abnormal & Total & Abnormal \\
\hline \multirow[t]{2}{*}{ Intercross } & Day 9 & 32 & $\begin{array}{c}2 \\
(6 \%)\end{array}$ & $\begin{array}{c}8 \\
(25 \%)\end{array}$ & 0 & $\begin{array}{c}16 \\
(50 \%)\end{array}$ & 7 & $\begin{array}{c}6 \\
(19 \%)\end{array}$ & $6^{8}$ \\
\hline & Day $10-15$ & 25 & $\begin{array}{c}4 \\
(16 \%)\end{array}$ & $\begin{array}{c}8 \\
(32 \%)\end{array}$ & 0 & $\begin{array}{c}13 \\
(52 \%)\end{array}$ & 3 & $\begin{array}{c}0 \\
(0 \%)\end{array}$ & 0 \\
\hline \multirow[t]{3}{*}{ Backcross } & Day 9-11 & 65 & $\begin{array}{c}5 \\
(8 \%)\end{array}$ & $\begin{array}{c}32 \\
(49 \%)\end{array}$ & $8^{\| \prime}$ & $\begin{array}{c}28 \\
(43 \%)\end{array}$ & 15 & & \\
\hline & Day $12-15$ & 13 & $\begin{array}{c}1 \\
(8 \%)\end{array}$ & $\begin{array}{c}8 \\
(61 \%)\end{array}$ & 0 & $\begin{array}{c}4 \\
(31 \%)\end{array}$ & 0 & & \\
\hline & Birth (deduced) & 49 & & $\begin{array}{c}32 \\
(65 \%)\end{array}$ & & $\begin{array}{c}17 \\
(35 \%)\end{array}$ & & & \\
\hline
\end{tabular}

* Placenta were present but neither extraembryonic nor embryonic tissues were available for genotyping; these embryos were presumed abnormal. ₹ Either resorbed embryos or embryos exhibiting gross malformations. ${ }^{8}$ All six embryos were resorbed. "Six of the abnormal embryos were offspring of $(+/-)$ females and two were offspring of $(+/-)$ males. "Projected number of $(+/+)$ and $(+/-)$ mice reaching term presuming perinatal death of all abnormal embryos. 

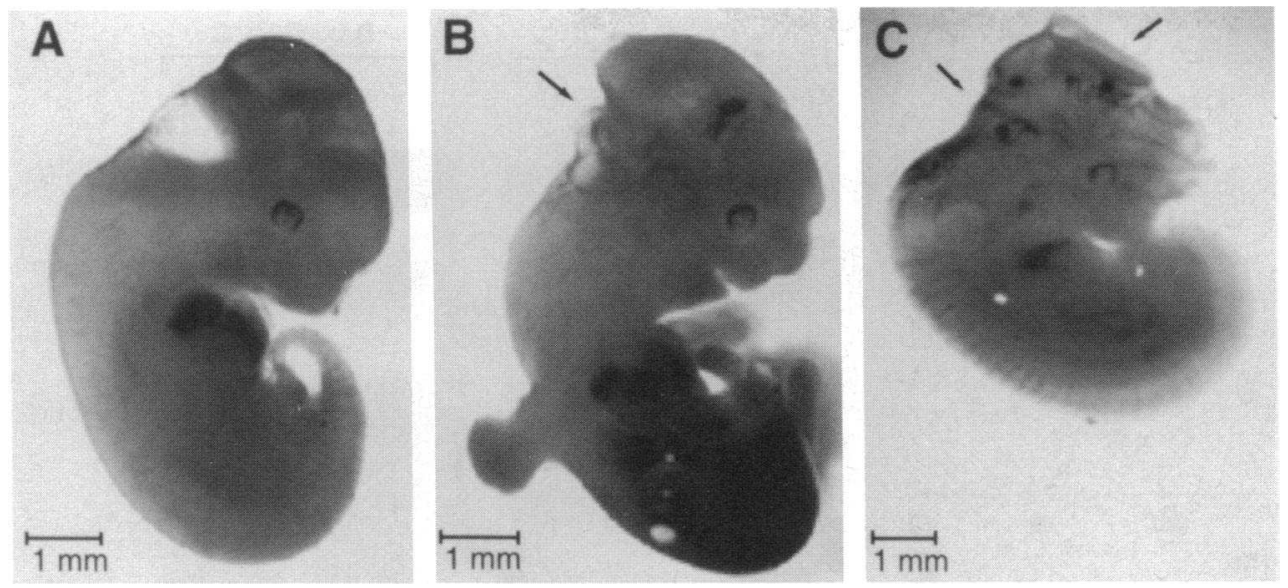

Figure 4. Incomplete closure of neural tubes in day 11 embryos from heterozygous intercrosses. Embryos were collected from pregnant mothers at gestational day 11 , fixed with $10 \%$ buffered formalin, and photographed under a stereomicroscope. (A) A wildtype embryo with normal morphology. ( $B$ ) A heterozygous embryo showing deformities in the hind portion of the head. $(C)$ A heterozygous embryo showing deformities in the hind and mid portions of the head. Embryos from $A$ and $B$ were littermates. The embryo shown in $C$ was from a different litter and appeared to be in a slightly later stage than embryos shown in $A$ and $B$. Arrows indicate the sites of gross abnormalities in the head region. The magnification of each embryo is indicated by the horizontal bar $(1 \mathrm{~mm})$ on the bottom left corner of each figure.

apo A-I, respectively. As shown in Table IV, there were no differences in the FCRs for HDL-CE or apo A-I between heterozygotes and wild-type littermates. In contrast, the TRs for HDL$\mathrm{CE}$ and apo A-I in heterozygotes were $~ 30$ and $34 \%$ lower, respectively, than in wild-type littermates. These data show that the reduction of HDL-C levels in heterozygotes is almost completely due to decreased HDL-CE and apo A-I TRs.

apo $B$ and apo A-I protein and mRNA levels in heterozygotes. The effects of one null apo B allele on plasma B-100, B-48, and apo A-I levels were analyzed by quantitative Western blot analysis. As shown in Fig. $6 \mathrm{~A}$, in heterozygous apo $\mathrm{B}$ knockout mice B-100 was reduced $70 \%$, B-48 50\%, and apo A-I $40 \%$ compared with wild-type littermates. Northern blot analysis revealed heterozygotes had a $50 \%$ decrease in apo B mRNA levels in both liver and intestine compared with wildtype littermates, but neither tissue showed a decrease in apo AI mRNA levels (Fig. 6, $B$ and $C$ ). These data suggest that the apo B gene dosage effect on plasma apo B levels is mainly transcriptional, whereas the decrease in plasma apo A-I in these mice is posttranscriptionally regulated.

Intestinal cholesterol absorption. To determine whether the decrease in intestinal apo B mRNA in heterozygotes diminished dietary cholesterol absorption, the double isotope method was used (31). Mice were dosed intragastrically with ${ }^{14} \mathrm{C}$-cholesterol and intravenously with ${ }^{3} \mathrm{H}$-cholesterol. The percentage of cholesterol absorption through the intestine was then assessed by the isotope ratio $\left({ }^{14} \mathrm{C} /{ }^{3} \mathrm{H}\right)$ present in the plasma (31). Previous studies in both rats (31) and mice (32) have shown that the ratios of ${ }^{3} \mathrm{H}$ to ${ }^{14} \mathrm{C}$ are independent of time for the 24-96$h$ interval. We therefore collected blood samples over this time span. As shown in Table V, both isotopes were cleared from plasma at the same rate as early as $21 \mathrm{~h}$ and the average isotope ratio indicated that the amount of cholesterol absorbed was about the same in heterozygotes $(64.1 \pm 7.0 \%)$ and wild-type littermates $(62.5 \pm 13.3 \%)$. The percentage of both isotopes remaining in the plasma at $69 \mathrm{~h}$ compared with the initial $21-\mathrm{h}$ time point was the same for both groups of animals. The percentage of ${ }^{14} \mathrm{C}$ and ${ }^{3} \mathrm{H}$ remaining in the plasma was $52 \pm 12$ and $52 \pm 13 \%$, respectively, for the heterozygotes and $51 \pm 15$ and $51 \pm 14 \%$, respectively, for wild-type animals. These results suggest that the presence of one null apo B allele does not decrease cholesterol absorption.

Table III. Dietary Influences on Lipoprotein in Heterozygotes and Wild-Type Littermates

\begin{tabular}{|c|c|c|c|c|c|c|c|c|}
\hline \multirow[b]{2}{*}{ Diet } & \multirow[b]{2}{*}{ apo B genotype } & \multirow[b]{2}{*}{$n$} & \multirow[b]{2}{*}{ Weight } & \multirow[b]{2}{*}{ TG* } & \multicolumn{4}{|c|}{ Cholesterol level } \\
\hline & & & & & Total & VLDL-C & LDL-C & HDL-C \\
\hline & & & grams & & & & & \\
\hline \multirow[t]{2}{*}{ Chow } & $+1+$ & 14 & $25 \pm 4$ & $57 \pm 14$ & $78 \pm 16$ & $8 \pm 3$ & $8 \pm 2$ & $62 \pm 14$ \\
\hline & $+1-$ & 9 & $23 \pm 4$ & $47 \pm 13$ & $49 \pm 13$ & $6 \pm 3$ & $5 \pm 2$ & $38 \pm 12$ \\
\hline \multirow[t]{2}{*}{ High fat ${ }^{\ddagger}$} & $+/+$ & 12 & $27 \pm 5$ & $67 \pm 23$ & $137 \pm 38$ & $23 \pm 11$ & $12 \pm 4$ & $103 \pm 31$ \\
\hline & $+1-$ & 7 & $27 \pm 5$ & $63 \pm 19$ & $91 \pm 31$ & $19 \pm 9$ & $8 \pm 3$ & $64 \pm 20$ \\
\hline \multicolumn{9}{|l|}{$P$ value ${ }^{8}$} \\
\hline Chow & $+/+$ vs. $+/-$ & & $<0.05$ & NS & $<0.0005$ & NS & $<0.005$ & $<0.0005$ \\
\hline High fat & $+/+$ vs. $+/-$ & & NS & NS & $<0.01$ & NS & $<0.05$ & $<0.005$ \\
\hline Chow vs. high fat & $+/+$ & & & NS & $<0.001$ & $<0.001$ & $<0.01$ & $<0.001$ \\
\hline Chow vs. high fat & $+1-$ & & & NS & $<0.01$ & $<0.01$ & $<0.05$ & $<0.01$ \\
\hline
\end{tabular}

${ }^{*} T G$, Triglyceride. ${ }^{\ddagger}$ Western-type diet: $21 \%$ fat and $0.15 \%$ cholesterol by weight. ${ }^{\S} P$ values from $t$ test. 


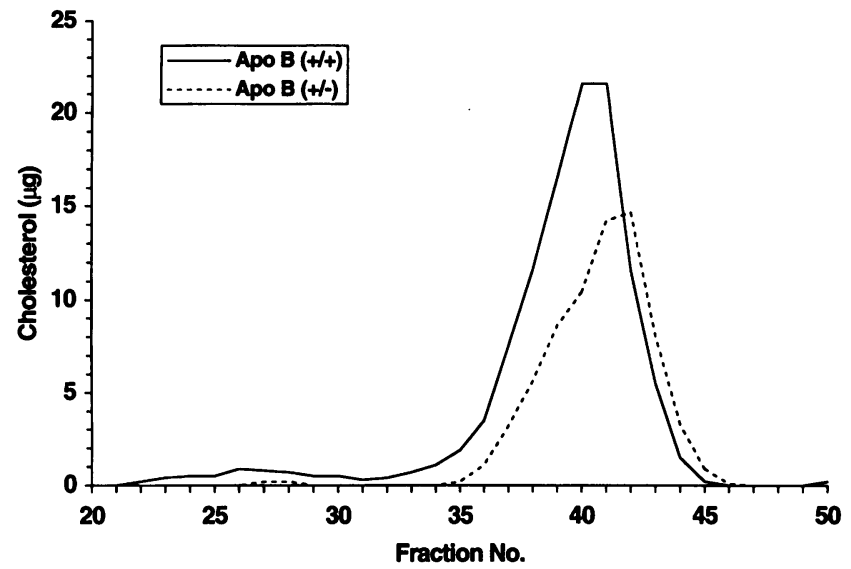

Figure 5. Lipoprotein profiles of heterozygotes and wild-type littermates. Pooled mouse plasma $(200 \mu \mathrm{l})$ from heterozygotes (dashed line) and wild-type littermates (solid line) were subjected to two Superose- 6 columns in series and $0.5 \mathrm{ml}$ of fractions was collected. The cholesterol in each fraction was measured and the amount (in micrograms) is shown on the $y$-axis. The fraction number is shown on the $x$-axis.

Diet responsiveness in heterozygotes. Chronic feeding of a high fat diet increases plasma cholesterol levels. To determine whether responsiveness to diet is altered in the presence of a defective apo B allele, heterozygous apo B knockout mice and wild-type littermates were challenged for 2 wk with a Westerntype diet containing $21 \%$ fat and $0.15 \%$ cholesterol (23). In the fasting state, plasma triglyceride levels were not significantly increased on the high fat compared with the chow diet in either the heterozygous or wild-type littermates (Table III). Compared with chow, the high fat diet significantly increased total cholesterol, VLDL-C, LDL-C, and HDL-C levels in heterozygous mice $86,217,60$, and $68 \%$, respectively, and wild-type mice $76,188,50$, and $66 \%$, respectively. Thus, both groups of mice responded similarly to a high fat diet and we conclude that the presence of a defective apo B allele does not alter diet responsiveness in the mouse.

\section{Discussion}

Gene targeting in ES cells was used to create mice with a null apo B allele. There were no live-born pups homozygous for the null allele, with death in utero occurring before day 9 . There was also a decreased frequency of live-born heterozygotes with

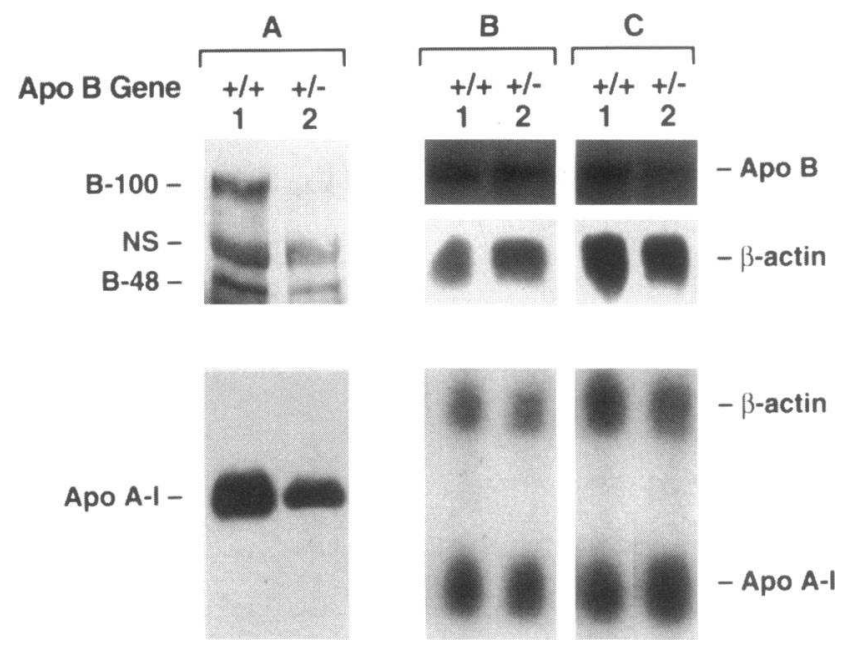

Figure 6. apo B and apo A-I protein and mRNA levels in heterozygotes and wild-type littermates. Western blot analysis $(A)$ was used to detect plasma apo B (top) and apo A-I (bottom). Plasma samples from both heterozygotes and wild-type littermates were subjected to a 5 or $10 \%$ SDS-PAGE for apo B or apo A-I detection, respectively, and then transferred to nitrocellulose membranes. Rabbit anti-rat apo B and antimouse apo A-I polyclonal antibodies were used to detect mouse apo $B$ and apo A-I, respectively. The band between B-100 and B-48 resulted from nonspecific binding $(N S)$ to the antibody and was not present when a different antibody was used. apo B genotypes for the animals are shown above each lane: $+1+$ for wild-type mice and $+/-$ for heterozygous knockouts. Northern blot analysis was used to detect apo B (top) and apo A-I (bottom) mRNA in liver $(B)$ and small intestine $(C)$. The amount of $\beta$-actin mRNA was used as an RNA loading control.

some embryos shown to have severe neural tube defects by days $10-15$ of gestation. Although most live-born heterozygotes were phenotypically normal, some were hydrocephalic. The clinical literature on patients with abetalipoproteinemia and homozygous hypobetalipoproteinemia does not describe fetal wastage or neural tube defects, therefore, the findings in the induced mutant mice were surprising. Since all heterozygous mice were derived from a single clone of ES cells, it is possible that another mutation accounting for the developmental abnormalities occurred during recombination in the creation of the null apo B allele. However, this is unlikely since a previous study using apo B gene targeting produced mutant mice that had decreased amounts of a truncated protein, B-70, also associated with developmental abnormalities (33). In that study onethird of B-70 homozygotes and a small number of B-70 hetero-

Table IV. In Vivo HDL Metabolism in Heterozygotes and Wild-Type Littermates

\begin{tabular}{|c|c|c|c|c|c|c|c|c|}
\hline Mouse & $n$ & Weight & HDL-C & HDL-CE FCR & HDL-CE TR* & apo A-I & apo A-I FCR & apo A-I TR \\
\hline & & grams & $m g / d l$ & pools $/ h$ & $U$ & $m g / d l$ & pools $/ h$ & $U$ \\
\hline apo $B(+/+)$ & 4 & $26 \pm 2.8$ & $77 \pm 13$ & $0.101 \pm 0.010$ & $5.365 \pm 0.490$ & $207 \pm 32$ & $0.092 \pm 0.011$ & $18.8 \pm 2.3$ \\
\hline apo $B(+1-)$ & 4 & $24 \pm 3.5$ & $49 \pm 8$ & $0.109 \pm 0.014$ & $3.739 \pm 0.936$ & $133 \pm 14$ & $0.093 \pm 0.017$ & $12.4 \pm 2.9$ \\
\hline$P$ value ${ }^{\S}$ & & NS & $<0.01$ & NS & $<0.05$ & $<0.01$ & NS & $<0.05$ \\
\hline
\end{tabular}

* TR is derived by multiplying HDL-C with HDL-CE FCR and the ratio of CE/TC (70\%). $U=\mathrm{mg} / \mathrm{dl} \times$ pools $/ \mathrm{h}$. ${ }^{\ddagger}$ Product of apo A-I FCR (pools/ h) and apo A-I level $(\mathrm{mg} / \mathrm{dl})$. ${ }^{\S} P$ values from $t$ test. 
zygotes that were live-born were hydrocephalic by 8 wk of age. In addition, a significant number of homozygous embryos (days 15.5-19.5) were exencephalic and died perinatally. In this report, we have confirmed that induced apo $B$ gene mutations in mice cause neural tube abnormalities in both heterozygotes and homozygotes.

The reason for the difference between apo B-deficient humans and mice is unknown. One possibility is that the human mutations thus far described in apo B are not null. Most of them allow expression of low levels of a truncated protein (14), whereas the induced mouse mutation we have created is a true null and hence might have a more severe phenotype. It is also possible that expression of the apo B gene in the yolk sac and fetal membranes $(34,35)$, which has been demonstrated, implies a role for apo B in fetal nutrition that might be more important in mice than in humans. Nutrients essential for development that might be transported by apo B could include the fat-soluble vitamins, such as vitamins $\mathrm{E}$ and/or $\mathrm{A}$, which are known to be low in abetalipoproteinemic and homozygous hypobetalipoproteinemic patients $(1,14)$. Vitamin $\mathrm{E}$ deficiency is a potential cause of the developmental abnormalities observed, since exencephalus and hydrocephalus have been seen in offspring of vitamin E-deficient mothers $(36,37)$. Vitamin A deficiency is less likely because, although vitamin A regulates the expression of many genes (38), vitamin A-deficient mothers produce offspring that exhibit mainly ocular problems and gonad malformations, rather than neural tube defects (39).

In addition to defects in the central nervous system, infertility was observed in the majority of the male heterozygotes, whereas this was not present in female heterozygotes. Sterile male heterozygotes showed no gross abnormalities of the genitourinary system and normal appearing sperm were present in the epididymis (data not shown). Functional abnormality of the sperm may contribute to the infertility phenotype in these animals (Huang, L.-S., E. Voyiaziakis, H. L. Chen, E. M. Rubin, and $\mathrm{J}$. W. Gordon, manuscript in preparation). Fertility has not been raised as an issue in humans with low levels of LDL; however, it cannot be ruled out as systematic studies of this issue have never been carried out. The mechanism whereby plasma levels of apo B or LDL-C might be linked to fertility remains obscure.

Mice heterozygous for a null apo B allele have major abnormalities in their lipoprotein transport system. Although triglyceride levels were unaffected, compared with wild-type mice heterozygotes had decreased total, LDL-C, and HDL-C levels on both chow and high fat diets. Although the B-70 mice mentioned above had a similar lipoprotein pattern, this was some- what of a surprise since humans with heterozygous hypobetalipoproteinemia have decreased triglycerides and decreased total, VLDL-C, and LDL-C but have not been found to have consistently low HDL-C levels $(1,14)$. In some kindred, HDL-C is clearly normal and in others it is even elevated. In the mice the metabolic basis for the reduced LDL-C is presumably reduced synthesis of apo B-containing lipoprotein particles as reflected by the decreased apo B mRNA levels in both liver and intestine. Turnover studies indicated that the metabolic basis for the reduced HDL in the heterozygous apo B knockout mice was decreased HDL-CE and apo A-I transport rates. This suggests that reduced apo B synthesis leads to diminished flux of cholesterol ester through the HDL pool. Perhaps reduced numbers of apo B-containing particles cause decreased delivery of cholesterol to peripheral tissues and this diminishes the need for reverse transport of cholesterol from peripheral tissues to the liver via HDL. Alternatively, there could be a decrease in the flux of hepatic-derived cholesterol ester into the HDL pool. It appears that reduced apo B synthesis also decreases apo A-I synthesis posttranscriptionally, as the levels of apo A-I mRNA do not change in liver and intestine. However, it is also possible that a rapidly turning over pool of nascent HDL was inadequately labeled in our study with a resulting apparent decrease in apo A-I synthesis. We have previously reported decreased apo A-I transport in mice and humans switched from high to low fat diets and in mice treated with probucol $(25,40,41)$. Mechanistic studies in the mice revealed decreased hepatic synthesis without a change in hepatic or intestinal mRNA levels as in the heterozygous apo B knockout mice. It is conceivable that in all three cases fat flux through the liver is decreased, which might decrease apo A-I synthesis by affecting liver apo A-I mRNA translation or degradation of newly synthesized apo A-I.

apo $B$ is a logical candidate gene to play a role in diet responsiveness. apo B synthesis is required for long chain fatty acid absorption by the intestine and apo B deficiency in humans prevents the formation of intestinal chylomicrons and hepatic VLDL (1). Mice heterozygous for an apo B null allele with decreased intestinal and liver apo B mRNA provide a model to test whether half-normal levels of apo B synthesis influence diet responsiveness. Heterozygous mice did not fail to thrive nor did they have steattorrhea. They also had normal cholesterol absorption, and when switched from a low fat, low cholesterol, chow diet to a high fat, high cholesterol, Western-type diet they showed the same percent increase in total, VLDL, LDL, and HDL cholesterol levels as wild-type mice. Diet responsiveness and cholesterol absorption have never been studied in humans

Table V. Intestinal Cholesterol Absorption in Heterozygotes and Wild-Type Littermates

\begin{tabular}{|c|c|c|c|c|c|c|c|c|}
\hline \multirow[b]{2}{*}{ Mouse } & \multirow[b]{2}{*}{$n$} & \multirow[b]{2}{*}{$\mathrm{TC}^{\ddagger}$} & \multicolumn{6}{|c|}{${ }^{14} \mathrm{C} /{ }^{3} \mathrm{H}$-cholesterol $(\%)$ in plasma ${ }^{*}$} \\
\hline & & & $21 \mathrm{~h}$ & $39 \mathrm{~h}$ & $45 \mathrm{~h}$ & $62 \mathrm{~h}$ & $69 \mathrm{~h}$ & Mean \\
\hline & & $m g / d l$ & & & & & & \\
\hline apo $B(+/+)$ & 6 & $99.1 \pm 13.3^{8}$ & $59.7 \pm 12.6$ & $64.6 \pm 13.8$ & $64.2 \pm 14.2$ & $63.6 \pm 14.2$ & $60.3 \pm 14.4$ & $62.5 \pm 13.3$ \\
\hline apo B $(+/-)$ & 8 & $70.3 \pm 8.1^{8}$ & $61.3 \pm 7.0$ & $68.9 \pm 5.5$ & $64.1 \pm 9.7$ & $64.8 \pm 5.0$ & $61.5 \pm 6.5$ & $64.1 \pm 7.0$ \\
\hline
\end{tabular}

${ }^{*}{ }^{14} \mathrm{C}$-cholesterol was orally fed and ${ }^{3} \mathrm{H}$-cholesterol intravenously injected to fasted mice. No significant difference of ${ }^{14} \mathrm{C} /{ }^{3} \mathrm{H}$-cholesterol was observed between two groups at any time point. ${ }^{\ddagger} T C$, total cholesterol. ${ }^{\S} P$ value from $t$ test is $<0.001$. 
with heterozygous hypobetalipoproteinemia, but our studies in mice suggest that within a twofold range the amount of apo $B$ does not play a role in diet responsiveness.

While this work was in preparation, Farese et al. (15) reported embryonic lethality in apo B knockout homozygotes, but not heterozygotes. Homozygous embryos were detectable at a later gestational stage $(>13.5 \mathrm{~d})$ and the abnormalities of homozygous embryos were less severe compared with those shown in this report. Two possibilities, alone or in combination, might have led to the observed differences. The first is differences in genetic background of the mice analyzed. The mice reported by Farese et al. (15) were derived from intercrosses between $\mathrm{F} 1$ heterozygotes and contained equal amounts of genetic background from both parental strains. In contrast, the mice reported here were derived from backcrosses and contained more genetic materials from the $\mathrm{C} 57 \mathrm{BL} / 6 \mathrm{~J}$ strain. The second is that different targeting vectors were used in these reports. Farese et al. (15) used an insertion vector to disrupt the apo $B$ gene in intron 4, whereas a replacement vector was used to delete the first three exons of the apo B gene in this report. The presence of the first four exons might allow translation of an extremely small truncated apo B protein which could be functional. It has also been shown that repair processes are more likely to occur in the insertion vector-targeted genes during the recombination event than in the replacement vectortargeted genes (42). In addition, we found that reduced apo B production did not affect intestinal cholesterol absorption and/ or the responsiveness to high fat challenge in heterozygous animals. In the report by Farese et al. (15), heterozygotes were resistant to diet-induced hypercholesterolemia. We speculate that the observed differences were mainly due to differences in the components of the diet used by each group.

In summary, we have created a knockout mouse model to study the role of apo B in the body and have identified a number of possible functions for this apolipoprotein not suspected based on previous studies of apo B-deficient humans. apo B may play a role in fetal nutrition and may be required for embryonic development, specifically for neural tube closure. apo B may also be involved in male fertility. Reduced apo B production may also influence HDL-C levels by decreasing HDL-CE and apo A-I transport. Somewhat contrary to expectations, we also found that decreased apo B production did not diminish cholesterol absorption or alter diet responsiveness. The apo B knockout mouse model provides a system to explore the mechanisms underlying these postulated new functions of apo B.

\section{Acknowledgments}

We thank Dr. Andrew Plump for his advice on the ES cells and gene targeting techniques, and Dr. Annmarie Walsh and Ms. Michele Inserra from the Transgenic Service Laboratory for microinjections of ES cells.

This work was supported by National Institutes of Health grant HL36461 for J. L. Breslow and Grant-In-Aid from the American Heart Association, New York City Affiliate for L.-S. Huang. L.-S. Huang is an Established Scientist of the American Heart Association, New York City Affiliate.

\section{References}

1. Kane, J. P., and R. J. Havel. 1989. Disorders of the biogenesis and secretion of lipoproteins containing the B apolipoproteins. In The Metabolic Basis of Inherited Disease. C. R. Scriver, A. R. Beaudet, W. S. Sly, D. Valle, J. B. Stanbury,
J. B. Wyngaarden, and D. S. Frederickson, editors. McGraw-Hill, New York. 1139-1164.

2. Knott, T. J., R. J. Pease, L. M. Powell, S. C. Wallis, S. C. Rall, T. L. Innerarity, B. D. Blackhart, W. H. Taylor, Y. Marcel, R. Miline, et al. 1986. Complete protein sequence and identification of structural domains of human apo B. Nature (Lond.). 323:734-738.

3. Yang, C., S. H. Chen, S. H. Gianturco, W. A. Bradley, J. T. Sparrow, M. Tanimura, W. Li, D. A. Sparrow, H. DeLoof, M. Rosseneu, et al. 1986. Sequence, structure, receptor-binding domains and internal repeats of human apo B-100. Nature (Lond.). 232:738-742.

4. Blackhart, B. D., E. M. Ludwig, V. R. Pierotti, L. Caiati, M. A. Onaasch, S. C. Wallis, L. Powell, R. Pease, T. J. Knott, M. Chu, et al. 1986. Structure of the human apo B gene. J. Biol. Chem. 261:15364-15367.

5. Chen, S. H., G. Habib, C. Yang, Z. Gu, B. R. Lee, S. Weng, S. R. Silberman, S. J. Cai, J. P. Deslypere, M. Rosseneu, et al. 1987. Apo B-48 is the product of a messenger RNA with an organ-specific in-frame stop codon. Science (Wash. DC). 238:363-366

6. Powell, L. M., S. C. Wallis, R. J. Pease, Y. H. Edwards, T. J. Knott, and J. Scott. 1987. A novel form of tissue-specific RNA processing produces apo B48 in intestine. Cell. 50:831-840.

7. Davidson, N., L. Powell, S. Wallis, and J. Scott. 1988. Thyroid hormone modulates the introduction of a stop codon in rat liver apo B mRNA. J. Biol. Chem. 263:13482-13485.

8. Heiss, G., and H. A. Tyroler. 1982. Are apolipoproteins useful for evaluating ischemic heart disease? A brief overview of the literature. In Proceedings of the Workshop on Apolipoprotein Quantification. National Institutes of Health, Bethesda, MD. NIH Publication. 83-1266. 7-24.

9. Young, S. G. 1990. Recent progress in understanding apolipoprotein B. Circulation. 82:1574-1594.

10. Soria, L. F., E. H. Ludwig, H. R. G. Clarke, G. L. Vega, S. M. Grundy, and B. J. McCarthy. 1989. Association between a specific apolipoprotein B mutation and familial defective apolipoprotein B-100. Proc. Natl. Acad. Sci. USA. 86:587-591.

11. Wetterau, J. R., L. P. Aggerbeck, M. Bouma, C. Eisenberg, A. Munck, M. Hermier, J. Schmitz, G. Gay, D. R. Rader, and R. E. Gregg. 1992. Absence of microsomal triglyceride transfer protein in individuals with abetalipoproteinemia. Science (Wash. DC). 258:999-1001.

12. Sharp, D., L. Blinderman, K. A. Combs, B. Kienzle, B. Ricci, K. WagerSmith, C. M. Gil, C. W. Turck, M. Bouma, D. J. Rader, et al. 1993. Cloning and gene defects in microsomal triglyceride transfer protein associated with abetalipoproteinaemia. Nature (Lond.). 365:65-69.

13. Shoulders, C. C., D. J. Brett, J. D. Bayliss, T. M. E. Narcisi, A. Jarmuz, T. T. Grantham, P. R. D. Leoni, S. Bhattacharya, R. J. Pease, P. M. Cullen, et al. 1993. Abetalipoproteinemia is caused by defects of the gene encoding the 97 $\mathrm{kDa}$ subunit of a microsomal triglyceride transfer protein. Hum. Mol. Genet. 2:2109-2116.

14. Linton, M. F., R. V. Farese, Jr., and S. G. Young. 1993. Familial hypobetalipoproteinemia. J. Lipid Res. 34:521-541.

15. Farese, R. V., Jr., S. L. Ruland, L. M. Flynn, R. P. Stokowski, and S. G. Young. 1995. Knockout of the mouse apolipoprotein B gene results in embryonic lethality in homozygotes and protection against diet-induced hypercholesterolemia in heterozygotes. Proc. Natl. Acad. Sci. USA. 92:1774-1778.

16. Ludwig, E. H., B. Levy-Wilson, T. Knott, B. D. Blackhart, and B. J. McCarthy. 1991. Comparative analysis of sequences at the $5^{\prime}$ end of the human and mouse apolipoprotein B genes. DNA Cell Biol. 10:329-338.

17. Tybulewicz, V. L. J., C. E. Crawford, P. K. Jackson, R. T. Bronson, and R. C. Mulligan. 1991. Neonatal lethality and lymphopenia in mice with a homozygous disruption of the c-abl proto-oncogene. Cell. 65:1153-1163.

18. Li, E., T. H. Bestor, and R. Jaenisch. 1992. Targeted mutation of the DNA methyltransferase gene results in embryonic lethality. Cell. 69:915-926.

19. Robertson, E. J. 1987. Embryo-derived stem cell lines. In Teratocarcinomas and Embryonic Stem Cells: A Practical Approach. E. J. Robertson, editor. IRL Press, Oxford. 71-112.

20. Huang, L.-S., D. A. Miller, G. A. Bruns, and J. L. Breslow. 1986. Mapping of the human APOB gene to chromosome $2 p$ and demonstration of a two-allele restriction fragment length polymorphism. Proc. Natl. Acad. Sci. USA. 83:644648.

21. Bradley, A. 1987. Production and analysis of chimeric mice. In Teratocarcinomas and Embryonic Stem Cells: A Practical Approach. E. J. Robertson, editor. IRL Press, Oxford. 113-151.

22. Prophet, B., B. Mills, J. B. Arrington, and L. H. Sobin. 1992. Armed Forces Institute of Pathology Laboratory Methods in Histotechnology. American Registry of Pathology, Washington, DC.

23. Plump, A. S., J. D. Smith, T. Hayek, K. Aalto-Setala, A. Walsh, J. G. Verstuyft, E. M. Rubin, and J. L. Breslow. 1992. Severe hypercholesterolemia and atherosclerosis in apolipoprotein E-deficient mice created by homologous recombination in ES cells. Cell. 71:343-353.

24. Heinemann, T., S. Metzger, E. A. Fisher, J. L. Breslow, and L.-S. Huang. 
1994. Alternative polyadenylation is a major cause of apo B-48 formation in rat hepatoma cell lines transfected with human apo B-100 minigenes. J. Lipid Res. 35:2200-2211.

25. Hayek, T., Y. Ito, N. Azrolan, R. B. Verdery, K. Aalto-Setäla, A. Walsh, and J. L. Breslow. 1993. Dietary fat increases high density lipoprotein (HDL) levels both by increasing the transport rates and decreasing the fractional catabolic rates of HDL cholesterol ester and apolipoprotein (apo) A-I. J. Clin. Invest. 91:1665-1671.

26. Jiao, S., T. G. Cole, R. T. Kitchens, B. Pfleger, and G. Schonfeld. 1990. Genetic heterogeneity of lipoproteins in inbred strains of mice: analysis by gelpermeation chromatography. Metab. Clin. Exp. 39:155-160.

27. Matthews, C. M. 1957 . The theory of tracer experiments with ${ }^{131}$ I-labeled plasma proteins. Phys. Med. Biol. 2:36-53.

28. Laemmli, U. K. 1970. Cleavage of structural proteins during the assembly of the head of $\mathrm{T}_{4}$. Nature (Lond.). 227:680-685.

29. Towbin, H., T. Staehelin, and T. Gordon. 1979. Electrophoretic transfer of proteins from polyacrylamide gels to nitrocellulose sheets: procedure and some applications. Proc. Natl. Acad. Sci. USA. 76:4350-4355.

30. Chomczynski, P., and N. Sacchi. 1987. Single-step method of RNA isolation by acid guanidinium thiocyanate-phenol-chloroform extraction. Anal. Biochem. 162:156-159.

31. Zilversmit, D. B. 1972. A single blood sample dual isotope method for the measurement of cholesterol absorption in rats. Proc. Soc. Exp. Biol. Med. 140:862-865.

32. Aalto-Setäla, K., C. L. Bisgaier, A. Ho, K. A. Kieft, M. G. Traber, H. J. Kayden, R. Ramakrishnan, A. Walsh, A. D. Essenburg, and J. L. Breslow. 1994 Intestinal expression of human apolipoprotein A-IV in transgenic mice fails to influence dietary lipid absorption or feeding behavior. J. Clin. Invest. 93:17761786

33. Homanics, G. E., T. J. Smith, S. H. Zhang, D. Lee, S. G. Young, and N.
Maeda. 1993. Targeted modification of apolipoprotein B gene results in hypobetalipoproteinemia and developmental abnormalities in mice. Proc. Natl. Acad. Sci. USA. 90:2389-2393.

34. Hopkins, B., A. L. Brice, P. N. Schofield, F. E. Baralle, and C. F. Graham. 1987. Identity of cells containing apolipoprotein B messenger RNA in 6- to 12week postfertilization human embryos. Development (Camb.). 100:83-93.

35. Demmer, L. A., M. S. Levin, J. Elovson, M. A. Reuben, A. J. Lusis, and J. I. Gordon. 1986. Tissue-specific expression and developmental regulation of the rat apolipoprotein B gene. Proc. Natl. Acad. Sci. USA. 83:8102-8106.

36. Cheng, D. W., and B. H. Thomas. 1953. Relationship of time of therapy to teratogeny in maternal avitaminosis E. Proc. lowa Acad. Sci. 60:290-299.

37. Verma, K., and D. W. King. 1967. Disorders of the developing nervous system of vitamin E-deficient rats. Acta Anat. 67:623-635.

38. Hofmann, C., and G. Eichele. 1994. Retinoids in development. In The Retinoids: Biology, Chemistry and Medicine. M. B. Sporn, A. B. Roberts, and D. S. Goodman, editors. Raven Press, Ltd., New York. 387-441.

39. Wilson, J. G., C. B. Roth, and J. Warkany, 1953. An analysis of the syndrome of malformations induced by maternal vitamin A deficiency. Effects of restoration of vitamin A at various times during gestation. Am. J. Anat. 92:189217.

40. Brinton, E. A., S. Eisenberg, and J. L. Breslow. 1990. A low-fat diet decreases high density lipoprotein (HDL) cholesterol levels by decreasing HDL apolipoprotein transport rates. J. Clin. Invest. 85:144-151.

41. Hayek, T., T. Chajek-Shaul, A. Walsh, N. Azrolan, and J. L. Breslow. 1991. Probucol decreases apo A-I transport rate and increases HDL cholesteryl ester fractional catabolic rate in control and human apo A-I transgenic mice. Arterioscler. Thromb. 11:1295-1302.

42. Deng, C., K. R. Thomas, and M. R. Capecchi. 1993. Location of crossovers during gene targeting with insertion and replacement vectors. Mol. Cell. Biol. $13: 2134-2140$ 